\title{
Morphology evolution of PS-b-PDMS block copolymer and its hierarchical directed self-assembly on block copolymer templates
}

Rasappa, Sozaraj; Schulte, Lars; Borah, Dipu; Hulkkonen, Hanna; Ndoni, Sokol; Salminen, Turkka; Senthamaraikanan, Ramsankar; Morris, Michael A.; Niemi, Tapio

Published in:

Microelectronic Engineering

Link to article, DOI:

10.1016/j.mee.2018.02.002

Publication date:

2018

Document Version

Peer reviewed version

Link back to DTU Orbit

Citation (APA):

Rasappa, S., Schulte, L., Borah, D., Hulkkonen, H., Ndoni, S., Salminen, T., Senthamaraikanan, R., Morris, M. A., \& Niemi, T. (2018). Morphology evolution of PS-b-PDMS block copolymer and its hierarchical directed selfassembly on block copolymer templates. Microelectronic Engineering, 192, 1-7. https://doi.org/10.1016/j.mee.2018.02.002

\section{General rights}

Copyright and moral rights for the publications made accessible in the public portal are retained by the authors and/or other copyright owners and it is a condition of accessing publications that users recognise and abide by the legal requirements associated with these rights.

- Users may download and print one copy of any publication from the public portal for the purpose of private study or research.

- You may not further distribute the material or use it for any profit-making activity or commercial gain

- You may freely distribute the URL identifying the publication in the public portal 


\section{Accepted Manuscript}

Morphology evolution of PS-b-PDMS block copolymer and its hierarchical directed self-assembly on block copolymer templates

Sozaraj Rasappa, Lars Schulte, Dipu Borah, Hanna Hulkkonen, Sokol Ndoni, Turkka Salminen, Ramsankar Senthamaraikanan, Michael A. Morris, Tapio Niemi

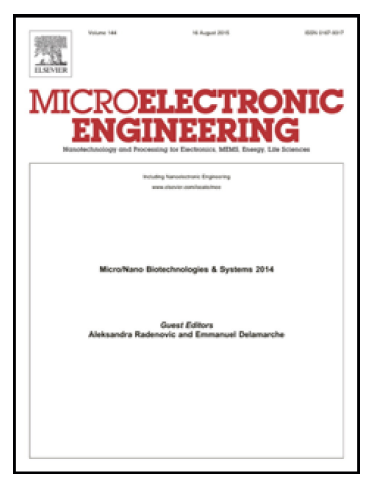

PII: S0167-9317(18)30062-5

DOI: https://doi.org/10.1016/j.mee.2018.02.002

Reference: MEE 10729

To appear in: Microelectronic Engineering

Received date:

3 October 2017

Revised date:

2 February 2018

Accepted date:

3 February 2018

Please cite this article as: Sozaraj Rasappa, Lars Schulte, Dipu Borah, Hanna Hulkkonen, Sokol Ndoni, Turkka Salminen, Ramsankar Senthamaraikanan, Michael A. Morris, Tapio Niemi , Morphology evolution of PS-b-PDMS block copolymer and its hierarchical directed self-assembly on block copolymer templates. The address for the corresponding author was captured as affiliation for all authors. Please check if appropriate. Mee(2017), https://doi.org/10.1016/j.mee.2018.02.002

This is a PDF file of an unedited manuscript that has been accepted for publication. As a service to our customers we are providing this early version of the manuscript. The manuscript will undergo copyediting, typesetting, and review of the resulting proof before it is published in its final form. Please note that during the production process errors may be discovered which could affect the content, and all legal disclaimers that apply to the journal pertain. 
Morphology evolution of PS- $b$-PDMS block copolymer and its hierarchical directed selfassembly on block copolymer templates

Sozaraj Rasappa ${ }^{*}$, Lars Schulte ${ }^{2,3}$, Dipu Borah ${ }^{4}$, Hanna Hulkkonen $^{1}$, Sokol Ndoni ${ }^{2,3}$, Turkka Salminen ${ }^{1}$, Ramsankar Senthamaraikanan ${ }^{4}$, Michael A Morris ${ }^{4}$ and Tapio Niemi ${ }^{1 *}$

${ }^{1}$ Laboratory of Photonics, Tampere University of Technology, P. O. Box 692, FI-33101, Finland.

${ }^{2}$ Department of Micro and Nanotechnology, Technical University of Denmark, DK-2800 Kgs, Lyngby, Denmark.

${ }^{3}$ Center for Nanostructured Graphene CNG, Technical University of Denmark, DK-2800 Kgs, Lyngby, Denmark.

${ }^{4}$ AMBER Centre and CRANN, Trinity College Dublin, Dublin 2, Ireland.

*Corresponding Authors: sozaraj.rasappa@tut.fi (SR), tapio.k.niemi@tut.fi (TN)

\begin{abstract}
:

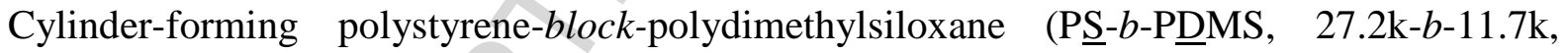
SD39) block copolymer having a total molecular weight of $39 \mathrm{~kg} \mathrm{~mol}^{-1}$ was exploited to achieve in-plane morphologies of lines, dots and antidots. Brush-free self-assembly of the SD39 on silicon substrates was investigated using solvents that were PS or PDMS selective, neutral and non-solvents based on their Hansen solubility parameters. The different morphologies were achieved with annealing times ranging from $10 \mathrm{~min}$ to $1 \mathrm{~h}$ at room temperature. The SD39 patterns were used as an etch mask for transferring the pattern into the underlying substrate. Directed self-assembly and hierarchical directed self-assembly on block copolymer templates for confinement of dots was successfully demonstrated. The strategy for achieving multiple morphologies using one BCP by mere choice of the annealing
\end{abstract}


solvents on unmodified substrates provides a simplified method for surface nanopatterning, templated growth of nanomaterials and nanofabrication.

(Keywords: block copolymer; hierarchical self-assembly; Hansen solubility; selective solvent)

\section{Introduction:}

In recent years, block copolymers (BCPs) have been extensively studied as a cost effective patterning platform for the fabrication of ultra-small device structures [1-4]. BCPs are covalently coupled molecules that can self-organize and form periodic patterns [5]. The size and shape of the final morphology of the $\mathrm{BCP}$ can be precisely tuned by its molecular weight and volume fraction of the blocks $[6,7]$. The size of the structures formed by the micro-phase separation of the BCPs are typically in the range of $5 \mathrm{~nm}$ to $100 \mathrm{~nm}[8]$ enabling the production of sub-10 $\mathrm{nm}$ feature sizes [9]. The spin coated BCP film is disordered but it can be organized by thermal annealing, solvent annealing or solvo-thermal annealing [10-13]. However, controlling the orientation of the BCP blocks in thin films, long-range ordering and point defects are still a challenge $[\mathbf{1 4}, \mathbf{1 5}$. Ordered BCP thin films can act as a template for the fabrication of metal/metal-oxide nanostructures and as an etch mask for pattern transfer [16-19].

Among other BCPs, PS- $b$-PDMS has a high Flory-Huggins value $(\chi=0.29)$, which enables the formation of ultra-small feature sizes and sharply defined patterns due to the strong segregation force between the polymer blocks [20]. Furthermore, the PDMS block contains inorganic moieties (silicon) resulting in a good in-situ etch contrast for nanolithography [21]. Recent reports show a variety of morphologies such as spheres, cylinders, lamellae and perforated lamellae that were achieved by tuning the volume fractions of the blocks and by tailoring the surface chemistry of the substrate $[\mathbf{2 2}, \mathbf{2 3}]$. To direct the BCP towards the desired morphology and orientation, polymer brush layers or self-assembled monolayers are 
typically applied on the surface of the substrate [24, 25]. Asymmetric PS-rich PS-b-PDMS primarily produces in-plane and out-of-plane cylinders. Hexagonally perforated lamellae or antidots are more difficult to acquire using PS-rich BCPs and thus PDMS-rich BCPs are utilized to achieve the antidot structures $[\mathbf{1 4}, \mathbf{1 5}]$.

The present study highlights the means to control the morphology of the (Pㅍ- $b$-PDMS, 27.2k$b-11.7 \mathrm{k}$, SD39) thin film through solvent annealing in selected solvents without any surface pretreatment or complex top-coat processes which considerably increase the overall processing time. The solvents and solvent mixtures were selected to be either neutral or nonsolvents for both blocks or selective for one of the blocks based on their Hansen solubility parameters (HSP). The optimization of the BCP annealing conditions was conducted using BCP thin films on silicon (Si) substrates. The line, dot and antidot morphologies were then used as etch masks to transfer the nanopattern into the substrate. Directed self-assembly (DSA) and hierarchical directed self-assembly on SD39 templates shows regular alignment without any brush layer. This hierarchical directed self-assembly will help in developing quantum and nanoplasmonic structures.

\section{Experimental}

\section{Solvents / Polymer synthesis}

All chemicals and solvents used in the present investigation were purchased from SigmaAldrich and utilized as received without further purification. The tested solvents were: Cyclopentanone (Reagent plus, $\geq 99.9 \%$ ), N,N Dimethylformamide or dimethylformamide (anhydrous, 99.8\%), 1,4 Dioxane or dioxane (anhydrous, 99.8\%), Tetrahydrofuran (inhibitorfree, CHROMASOLV Plus, for HPLC, $\geq 99.9 \%$ ), Toluene (CHROMASOLV, for HPLC, 99.9\%), Hexane (for HPLC, $\geq 95 \%$ ), and Heptane (for HPLC, $\geq 99 \%$ ). Buffered Oxide Etchant or Buffered HF (BOE 7:1) was purchased from Microchemicals and used as received. The SD39 was synthesized by living anionic polymerization following a reported procedure [26, 
27]. The average molecular weights per block and the polydispersity index (PDI) were determined using size exclusion chromatography and a total molecular weight of $38.9 \mathrm{~kg}$ $\mathrm{mol}^{-1}\left(\mathrm{M}_{\mathrm{PS}}: 27.2 \mathrm{~kg} \mathrm{~mol}^{-1}\right.$ and $\mathrm{M}_{\mathrm{PDMS}}: 11.7 \mathrm{~kg} \mathrm{~mol}^{-1}$ ) and PDI of 1.03 were estimated.

\section{BCP template and nanopattern fabrication}

All Si substrates were polished single-crystal silicon with $\langle 100\rangle$ orientation, p-type doped and used without any surface pretreatment. The SD39 solution of $1 \mathrm{wt} \%$ in toluene was made and $20 \mu \mathrm{l}$ of the solution was directly spin coated at a spin speed of $2000 \mathrm{rpm}$ for $40 \mathrm{~s}$ resulting in a film thickness of $18 \mathrm{~nm}$. The BCP film thickness was measured by a laser ellipsometer (Rudolph Research AutoEL III) with a HeNe laser at a $70^{\circ}$ incident angle. The film thickness measurement was carried out in at least five different locations on each substrate and averaged. SD39 thin films were solvent annealed at room temperature $\left(21^{0}\right)$ between $10 \mathrm{~min}$ and $1 \mathrm{~h}$ in a tightly closed glass jar using solvents and solvent mixtures selected based on their Hansen solubility values. The glass jar for solvent annealing has a volume of $50 \mathrm{~cm}^{3}$ and was filled with 1-5 $\mathrm{ml}$ of monosolvent or solvent volumetric mixtures under saturated atmosphere. The annealed films were etched with $\mathrm{SF}_{6}$ plasma $(7 \mathrm{sccm})$ with $30 \mathrm{~W}$ RIE and $50 \mathrm{~W}$ ICP at $2.0 \mathrm{~Pa}$ (15 mTorr) pressure for $3 \mathrm{~s}$ to remove the PDMS wetting layer. Then the PS was selectively etched using $\mathrm{O}_{2}$ plasma for $10 \mathrm{~s}$ with $1200 \mathrm{~W}$ ICP and 50 W RIE powers at 2.0 Pa (15 mTorr) pressure (Oxford Plasmalab System 100, ICP). The application of $\mathrm{O}_{2}$ plasma will simultaneously oxidize the PDMS block. The oxidized PDMS was then used to etch $\mathrm{Si}$ using $\mathrm{SF}_{6}(15 \mathrm{sccm})$ and $\mathrm{O}_{2}(5 \mathrm{sccm})$ plasma with $20 \mathrm{~W}$ RIE and 300 W ICP powers at $0.66 \mathrm{~Pa}(5 \mathrm{mTorr})$ for $18 \mathrm{~s}$. Finally all of the samples were rinsed with $\mathrm{BOE}$ to remove any residual oxidized PDMS.

\section{Substrates for DSA}

The substrates have a low pressure chemical vapor deposited silicon nitride $\left(\mathrm{Si}_{3} \mathrm{~N}_{4}\right)$ coating (resistivity, $\rho=1 \times 10^{14}$ to $1 \times 10^{16} \Omega \mathrm{cm}$ ) on p-type silicon $<100>$ with a native surface 
oxide layer of $2 \mathrm{~nm}$. The topographically patterned $\mathrm{Si}_{3} \mathrm{~N}_{4}$ films with pitches in the range of 75-500 nm, variable mesa widths of 30-700 nm, and depth of $60 \mathrm{~nm}$ were fabricated via 193 nm UV-lithography and processed by means of conventional mask and etch techniques.

\section{Scanning Electron Microscopy (SEM)}

Top-down and tilted SEM images were obtained by using a field emission scanning electron microscope (Zeiss Ultra 55) with $3 \mathrm{kV}$ acceleration voltage. Unless otherwise stated, all SEM images are after PS removal and oxidation of the PDMS block. The dimensions were analyzed from the SEM images the dots and the antidots using Image $\mathrm{J}$ software.

\section{Results and discussion}

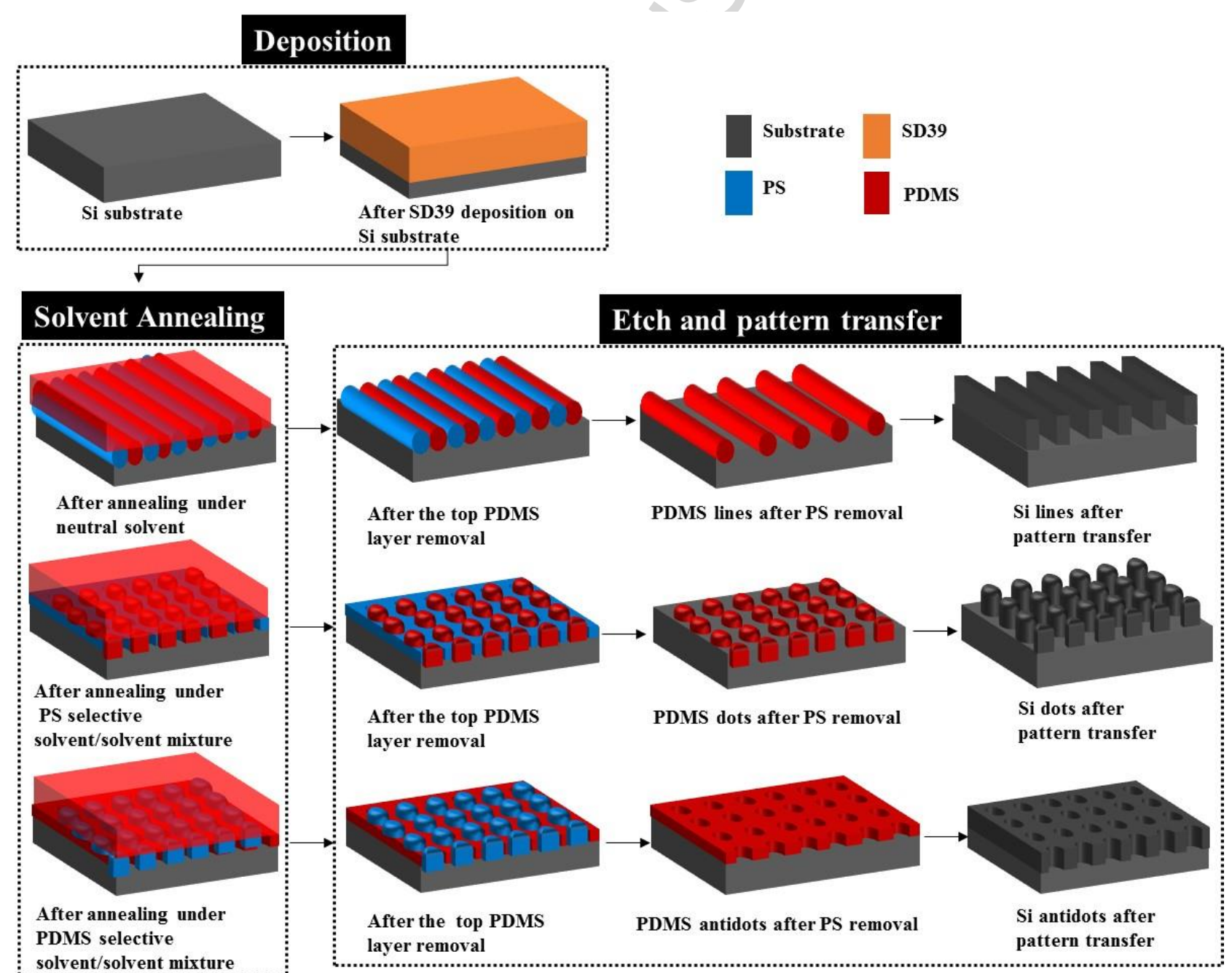

Scheme 1. The process flow of SD39 thin film deposition, solvent annealing, etch and pattern transfer. 
Scheme 1 illustrates the process flow of fabrication of nanostructures by SD39 including film deposition, solvent annealing and etch procedures. As outlined in Scheme 1, after annealing, the PDMS was observed to form a thin wetting layer on top at the air-polymer interface. This is attributed to the surface tension of PDMS $\left(\gamma_{C}=24 \mathrm{mNm}^{-1}\right)$ being lower than that of PS $\left(\gamma_{\mathrm{C}}\right.$ $=32.8 \mathrm{mNm}^{-1}$ ) [11]. Thereafter, a brief PDMS etch was applied to remove the top layer before the complete removal of PS by $\mathrm{O}_{2}$ plasma. The Hansen solubility parameters (HSP) for the solvents and solvent mixtures used here are listed in Table 1 and supporting information (SI).

Table 1. HSP of the solvents and Ra for PS and PDMS relative to the used solvents and solvent mixtures. Subscripts denote the volume ratio of the mixtures. Ra values below 4 indicates selective solvent and below 2 highly selective solvent.

\begin{tabular}{|c|c|c|c|c|c|c|}
\hline \multirow[t]{2}{*}{ Selectivity } & \multirow{2}{*}{$\begin{array}{l}\text { Solvent/Solvent } \\
\text { mixture/polymer }\end{array}$} & \multirow{2}{*}{$\frac{\underline{\delta}_{\mathrm{D}}}{\left[\mathrm{MPa}^{1 / 2}\right]}$} & \multirow{2}{*}{$\begin{array}{c}\underline{\delta}_{\mathbf{P}} \\
{\left[\mathbf{M P a}^{1 / 2}\right]}\end{array}$} & \multirow{2}{*}{$\begin{array}{c}\underline{\boldsymbol{\delta}}_{\mathbf{H}} \\
{\left[\mathbf{M P a}^{1 / 2}\right]}\end{array}$} & \multicolumn{2}{|c|}{$\mathbf{R a}$} \\
\hline & & & & & PS & PDMS \\
\hline \multirow[t]{2}{*}{ Neutral } & toluene & 18.0 & 1.4 & 2.0 & 5.2 & 5.0 \\
\hline & dioxane & 17.5 & 1.8 & 9.0 & 6.5 & 6.1 \\
\hline \multirow{5}{*}{ PS } & cyclopentanone & 17.9 & 11.9 & 5.2 & 5.9 & 12.6 \\
\hline & tetrahydrafura & 16.8 & 5.7 & 8.0 & 4.2 & 7.1 \\
\hline & cyclopentanone $_{1}$ :toluene ${ }_{1}$ & 17.9 & 6.6 & 3.6 & 1.0 & 7.8 \\
\hline & tetrahydrofuran :toluene $_{1}$ & 17.4 & 3.5 & 5 & 2.7 & 4.7 \\
\hline & dimethylformaide $_{1}$ :toluene & 17.7 & 7.5 & 6.6 & 2.7 & 8.5 \\
\hline \multirow{7}{*}{ PDMS } & & 14.9 & 0.0 & 0.0 & 9.1 & 4.6 \\
\hline & heptane & 15.3 & 0.0 & 0.0 & 8.7 & 4.2 \\
\hline & hexane $_{1}:$ toluene $_{1}$ & 16.5 & 0.7 & 1.0 & 6.6 & 3.3 \\
\hline & hexane $_{1}$ :toluene 2 & 16.7 & 0.9 & 1.3 & 6.1 & 3.4 \\
\hline & hexane $_{1}:$ toluene $_{3}$ & 17.2 & 1.05 & 1.5 & 5.7 & 3.8 \\
\hline & PS & 17.6 & 6.1 & 4.1 & - & - \\
\hline & PDMS & 15.9 & 0.0 & 4.1 & - & - \\
\hline
\end{tabular}


Based on the HSP values, we calculated the Hansen distance (Ra) of PS and PDMS relative to the used solvents and solvent mixtures. The Hansen distance is defined as, $\mathrm{Ra}=\left[4\left(\delta_{\mathrm{D}, \mathrm{Polymer}}\right.\right.$ $\left.\left.-\delta_{\mathrm{D}, \text { Solvent }}\right)^{2}+\left(\delta_{\mathrm{P}, \text { Polymer }}-\delta_{\mathrm{P}, \text { Solvent }}\right)^{2}+\left(\delta_{\mathrm{H}, \text { Polymer }}-\delta_{\mathrm{H}, \text { Solvent }}\right)^{2}\right]^{1 / 2}[\mathbf{2 8}]$ where $\delta_{\mathrm{D}}$ is the dispersive force factor, $\delta_{\mathrm{P}}$ is the dipole force factor and $\delta_{\mathrm{H}}$ is the hydrogen-bonding factor and calculated as described elsewhere $[\mathbf{2 9}, \mathbf{3 0}]$. A small Ra value indicates that the polymer is more soluble in the solvent [30]. The solvents and solvent mixtures were classified by comparing the calculated Ra values for PS and PDMS as selective (small Ra for one polymer), neutral (similar Ra) or non-solvents (large Ra for both polymers) as shown in Table 1. We observed

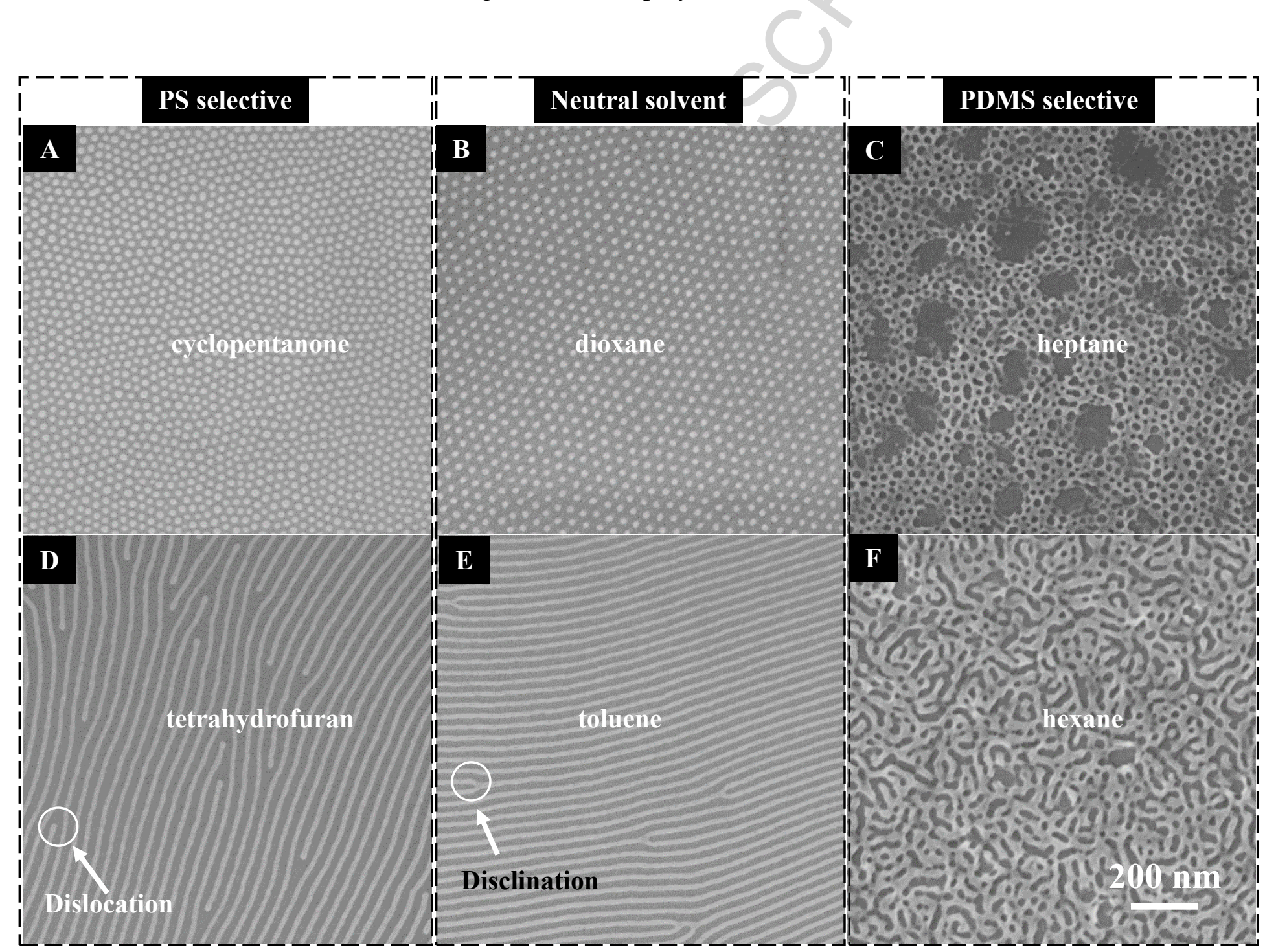

Figure 1. Top-down SEM images of the oxidized PDMS on the Si substrate. The line and the dot samples were annealed between $10 \mathrm{~min}$ and $18 \mathrm{~min}$. The antidot samples were annealed for $1 \mathrm{~h}$. 
that the annealing solvents which are PS selective and neutral lead to the formation of lines or dots whereas PDMS selective solvents formed antidots as depicted in Scheme 1. Figure 1 shows SEM images of the PDMS templates from the SD39 thin films annealed under PS selective, neutral and PDMS selective solvents. From Figures $1 \mathrm{~A} \& 1 \mathrm{D}$ it is evident that annealing under PS selective solvents such as cyclopentanone and tetrahydrofuran produced densely packed regular dots and irregular line structures with dislocation and disclination defects. SD39 switches between lines and dots for PS selective solvents since PS swells more than PDMS and the change in the effective volume fraction of PS shifts the polymer system from the cylinder phase towards the dot phase $[\mathbf{3 1}, \mathbf{3 2}]$. Neutral solvents such as dioxane and toluene forms dots and well aligned line patterns. Annealing with toluene produced welldefined PDMS lines with fewer defects than annealing with tetrahydrofuran. This is attributed to the mobility of PDMS chains which is limited under PS selective solvents and leads to better organization when switched to neutral solvent (Table 1) [7]. The line width, $<\mathbf{d}\rangle$, of the PDMS lines after annealed under toluene and tetrahydrofuran were the same $21 \pm 1 \mathrm{~nm}$. However, domain spacing $<\mathbf{L}_{\mathbf{0}}>$ for toluene is $36 \pm 1 \mathrm{~nm}$ but for tetrahydrofuran it is not uniform. Annealing under the PDMS selective solvents, such as hexane and heptane, produces an inverted dot morphology (antidots) although the ordering of the patterns is poor as observed from Figures $1 \mathrm{C} \& 1 \mathrm{~F}$. Annealing under PDMS selective solvent makes rubbery natured PDMS to flow more easily and enforcing the glassy PS chains to migrate. The intrinsically PS-rich SD39 behaves like a PDMS-rich under PDMS selective solvents but due to the limited mobility only poorly organized antidots were observed. Annealing in dimethylformamide which is a non-solvent for both blocks, resulted in a mixture of lines and dots as shown in Figure S1. This proves that a non-solvent can also be used to favor selfassembly and this could be due to its stronger $\delta_{\mathrm{H}}[\mathbf{3 3}]$. The inclusion of toluene as the second solvent in a dual solvent vapor annealing markedly improved the microphase separation in 
comparison to the mono solvents as shown in Figure 2. The irregular cylindrical pattern shown in Figure 1D obtained under PS selective tetrahydrofuran evolved into a conventional 'fingerprint' line morphology under volumetric mixture of tetrahydrofuran :toluene $_{1}$ (Figure 2A). This shows that the addition of toluene makes the tetrahydrofuran ${ }_{1}$ :toluene $_{1}$ solvent mixture highly selective to PS ( $\left.\operatorname{RapS}_{\mathrm{PS}}-2.7\right)$ which brought a uniform $\left\langle\mathbf{L}_{\mathbf{0}}\right\rangle$ of $36 \pm 1 \mathrm{~nm}$ as with toluene (Figure 1E). Interestingly, the mixed morphology of cylinders and dots under dimethylformamide (Figure S1) changed to well-ordered and shaped dots under dimethylformamide $_{1}$ :toluene ${ }_{1}$ vapors (Figure 2B) as the solvent changes from a non-solvent to highly PS selective (Raps- 2.7). The size of the PDMS dots under

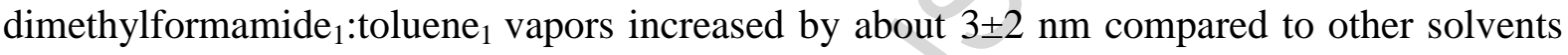
with a periodicity of $46 \pm 2 \mathrm{~nm}$. A similar variation in periodicity for PDMS structures was observed for cylinder forming PS-rich PS- $b$-PDMS and was documented elsewhere [7]. When switching from dioxane to solvent mixtures of dioxane ${ }_{1}$ :toluene ${ }_{1}$, the morphology evolved from dots to a mixture of lines and dots (Figures 1B \& S2) as Ra of dioxane $_{1}:$ toluene $_{1}$ is smaller than that of dioxane. This concludes that when the annealing solvent or solvent mixture is neutral or highly PS selective then the morphology evolves to lines, dots or mixture of lines and dots. The addition of a neutral solvent to a PDMS selective solvent enhances the chain mobility of both of the blocks in SD39 and resulted in antidot structures [34]. This is attributed to their asymmetric swelling behavior and changes in the effective volume fraction, which is due to the difference in affinities of the two blocks. Mixing heptane or hexane with toluene improved antidot formation (heptane 1 :toluene 2 , heptane $_{1}$ :toluene , hexane $_{1}:$ toluene $_{2}$, hexane :toluene $_{3}$ ) and both solvents produced identical morphologies, possibly because of their nearly similar Ra values (3.5 and 3.4) and their average antidot sizes were $32 \pm 2 \mathrm{~nm}$ and $31 \pm 2 \mathrm{~nm}$. As shown in figures $2 \mathrm{E} \& \mathrm{~S} 2$, solvent mixtures of hexane 1 :toluene ${ }_{2}$ and heptane :toluene $_{2}$ are highly selective to PDMS block 
favoring the formation of uniform antidot patterns. When the volume fraction of heptane and hexane increased in the mixtures, disordered structures or multilayers occurred (not shown here). On the other hand when the volume fraction of toluene was increased, mixed lines and disordered antidots were observed as shown in Figure $2 \mathbf{F} \boldsymbol{\&}$ S2. This is because the increase of toluene made the mixture less selective to PDMS. Furthermore, Figure 2E indicates that there is an optimum solvent ratio, where PS-rich SD39 produced uniform antidots. Other tested solvent ratios lead to mixed morphologies (Figure 2D \& 2F).

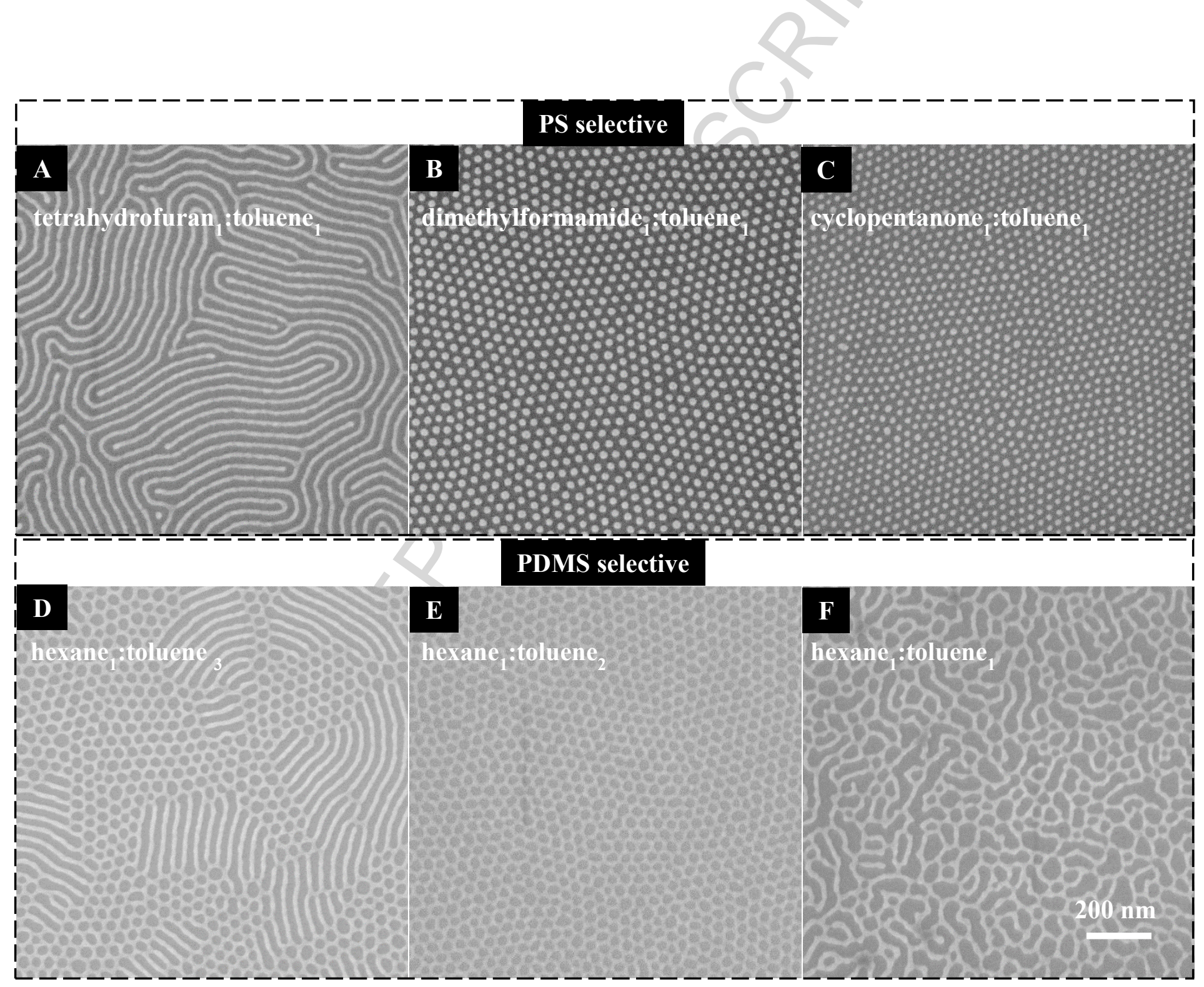

Figure 2: Top-down SEM images of the oxidized PDMS on the Si substrate. The lines and dots samples were annealed between $10 \mathrm{~min}$ and $18 \mathrm{~min}$ whereas the antidot samples were annealed for $1 \mathrm{~h}$. 
Results of the pattern transfer into Si substrate from oxidized PDMS are compiled in Figure

3. A plasma of $\mathrm{SF}_{6}$ and $\mathrm{O}_{2}$ was applied to etch the nanopatterns into the Si substrates with an etch depth of $21 \pm 2 \mathrm{~nm}$. This demonstrates that there is a good etch contrast between the oxidized PDMS mask and Si under the employed etching conditions. Figures 3A, 3C \&3E represents the large area top-down SEM images of Si lines, dots and antidots. Figures 3B, 3D $\& 3 \mathrm{~F}$ shows the corresponding cross-sectional SEM images of lines, dots and antidots. This

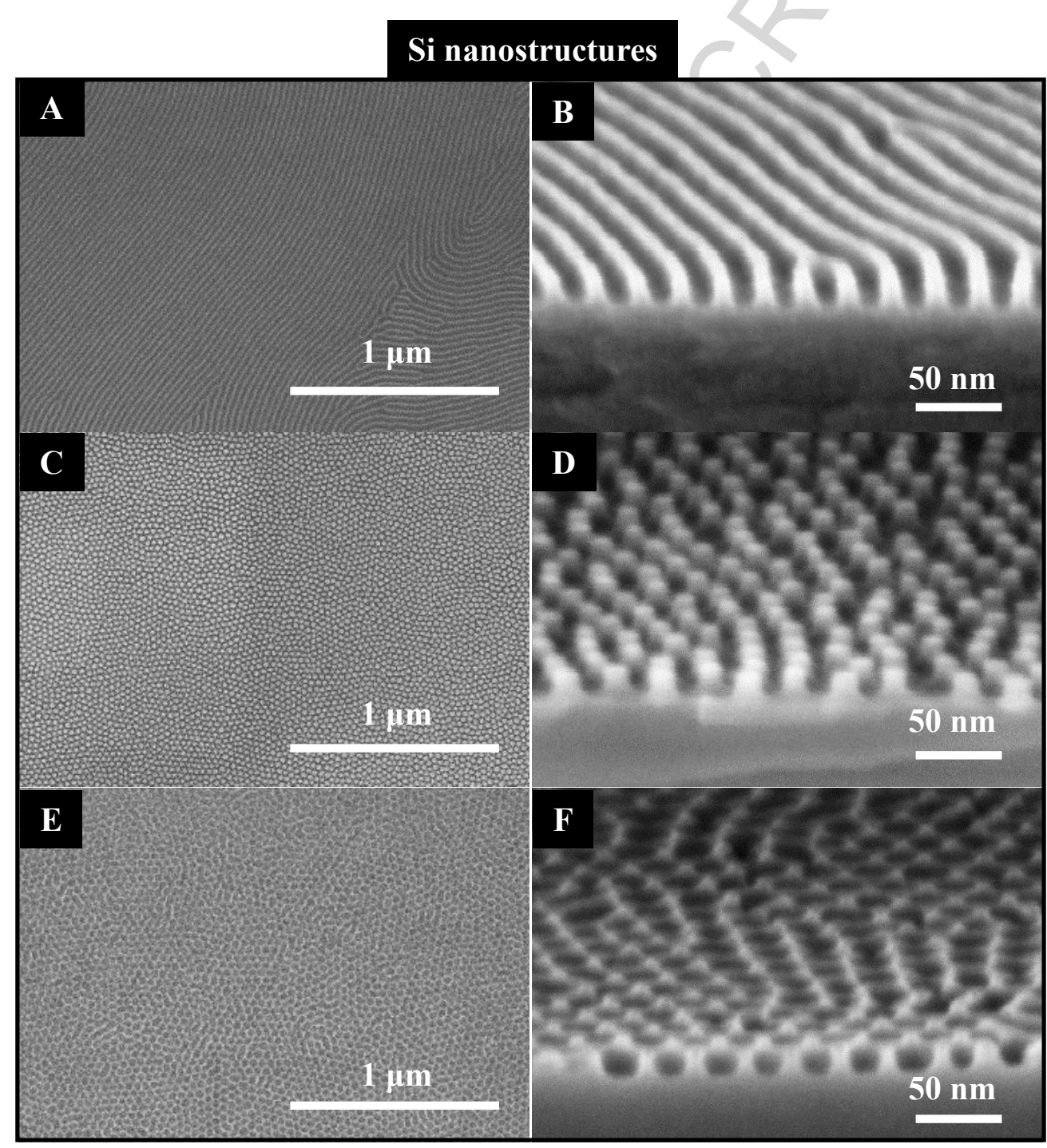

Figure 3: Top down and cross-sectional SEM images of the Si nanostructures. (A, C \& E) Top down SEM images of the lines, the dots and the antidots. (B, D \&F) Cross-sectional SEM images of the lines, the dots and the antidots. 
represents a significant breakthrough in the area of block copolymer lithography of achieving multiple morphologies by simply choosing annealing solvent based on its HSP.

\section{Hierarchical directed self-assembly on SD39 templates}

Directed self-assembly (DSA) on nanostructured templates supports the self-assembly of BCPs into longer range ordering. DSA has been extensively explored related to applications in microelectronics over the past few years $[\mathbf{2 0}, \mathbf{3 5}]$. Nanostructured templates can be made by conventional nanolithography techniques such as immersion photolithography, electronbeam lithography or nanoimprint lithography. However, down scaling their resolution below sub-20 nm is hard and alignment of individual nanofeatures of sub-10 nm is even more difficult. To advance the applications of the self-assembly of BCPs we made two experiments with DSA of SD39. First, we utilized the DSA substrates having 250-350 nm wide trenches 


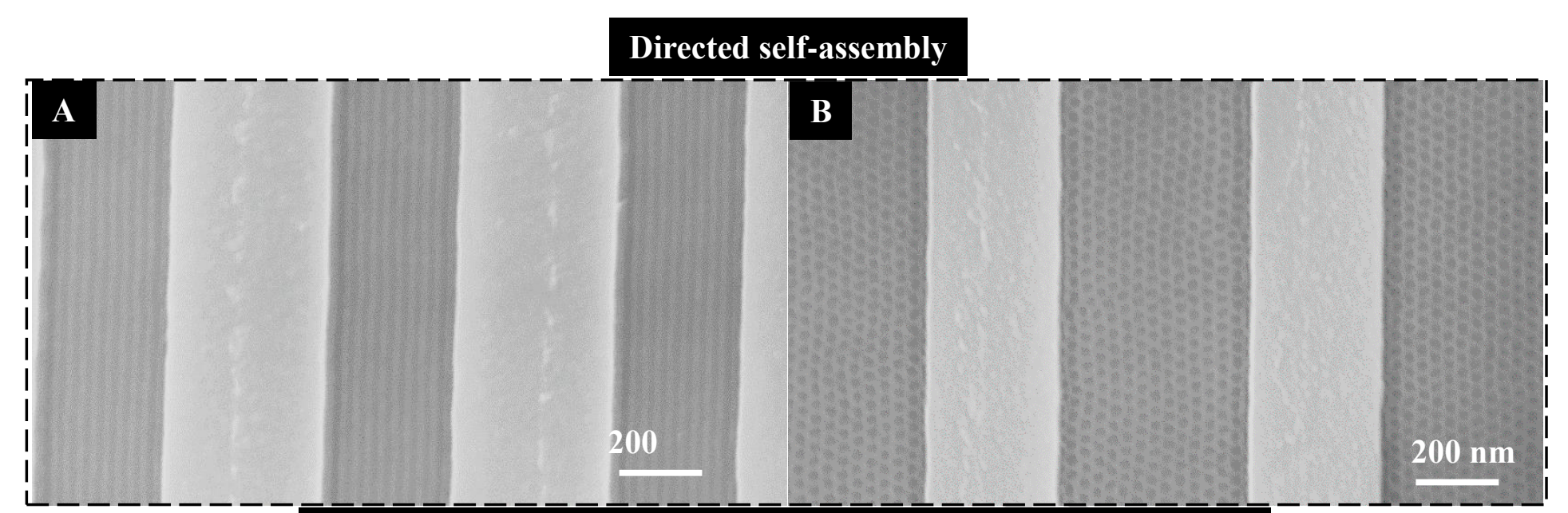

Hierarchical directed self-assembly on block copolymer templates

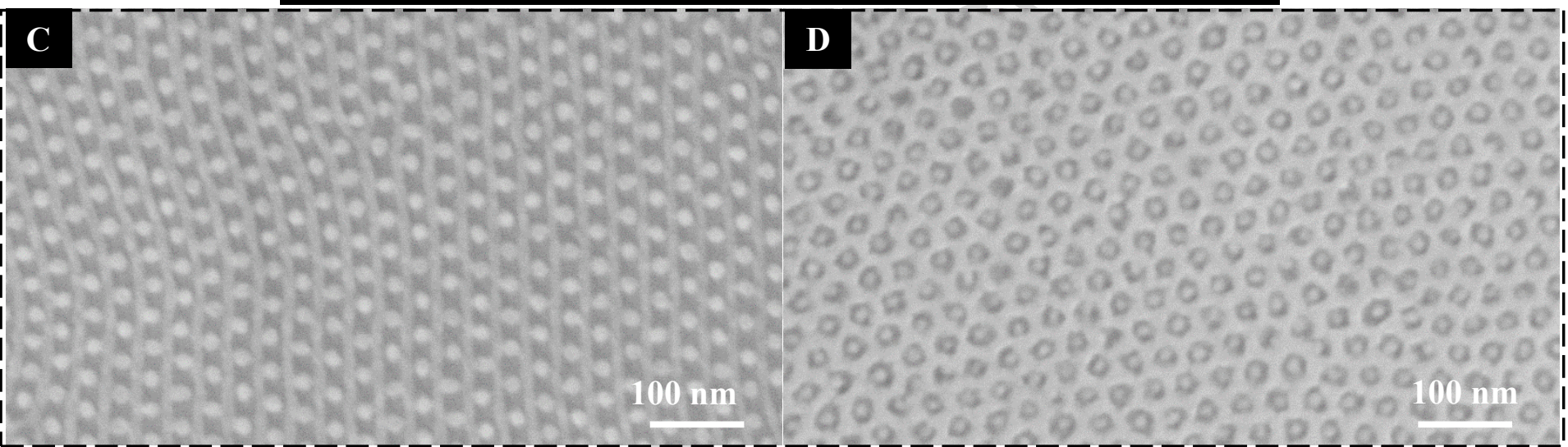

Figure 4: Directed and hierarchical directed self-assembly. (A\&B) SD39 lines and antidots aligned on graphoepitaxial trench substrate. (C\&D) Hierarchical directed self-assembly of dots in between lines and antidots of SD39 block copolymer templates.

in $\mathrm{Si}_{3} \mathrm{~N}_{4}$ film to direct the lines and the antidots. The results of annealing either under the PS selective or the PDMS selective solvent mixtures are shown in Figures 4A \& 4B. Wellordered alignment in the guiding trenches and morphology similar to the planar substrates can be observed. This demonstrates the long range lateral ordering on the templates made by conventional lithography. Second, we used the self-assembled lines and antidots of the oxidized PDMS as templates for hierarchical DSA of SD39. The hierarchical DSA results in self-alignment of the individual PDMS dots as shown in Figures 4C \& 4D. This approach supports the future applications in positioning nanostructures for semiconductor quantum technology and nanoplasmonics [36]. 


\section{Conclusions}

We have demonstrated brushfree self-assembly of a cylinder-forming PS- $b$-PDMS (SD39) having a variety of densely packed morphologies of lines, dots and antidots. These were achieved by simply selecting the favorable annealing solvents and solvent mixtures based on HSP. The relation between the nature of the solvent and the final morphology was concluded as: neutral and PS selective/highly PS selective solvents produce lines, dots or mixture of lines and dots, whereas PDMS selective/highly PDMS selective solvents exhibit only antidots. Direct nanopatterning of Si using the produced morphologies shows a good etch contrast between the oxidized PDMS and Si producing well defined nanopatterns. Moreover, directed and hierarchical directed self-assembly on block copolymer templates was demonstrated. This hierarchical directed self-assembly could be potential for quantum technologies, metal nanodots isolation and nanogap tuning. Overall, the realization of all morphologies in one BCP (SD39) based on HSP of the annealing solvents demonstrates a simple nanopatterning method for future nanofabrication applications.

\section{Acknowledgments:}

Financial support for this work is provided by Tampere University of Technology- TUT Postdoc Grant, Center for Nano-structured Graphene sponsored by the Danish National Research Foundation (Project DNRF58, by the EU FP7 NMP project) and Science Foundation Ireland (SFI) AMBER Centre (grant 12/RC/2278).

\section{References}

1. D. Borah, M. T. Shaw, S. Rasappa, R. Farrell, C. A. O'Mahony, C. M. Faulkner, M. Bosea, P. Gleeson, J. D. Holmes, M. A. Morris, J. Phys. D: Appl. Phys. 44 (2011) 174012-174024.

2. H. W. Li, W. T. S. Huck, W. T. S, Nano Lett. 4 (2004)1633-1636.

3. C. T. Black, ACS Nano 1 (2007) 147-150. 
4. D. J. C. Herr, Journal of Materials Research 26 (2011) 122-139.

5. S. O. Kim, H. H. Solak, M. P. Stoykovich, N. J. Ferrier, J. J. De Pablo, P. F. Nealey, Nature $424(2003) 411-414$.

6. Y. Someya, R. Mizuochi, H. Wakayama, S. Tadokoro, M. Kozawa, R. Sakamoto, Proc. of SPIE. 10146 (2017) 101461Y-1.

7. S. Jung, C. A. Ross, Adv. Mater. 21 (2009) 2540-2545.

8. X. M. Yang, S. Xiao, Y. Hsu, M. Feldbaum, K. Lee, D. Kuo, Journal of Nanomaterials 615896 (2013), Article ID 615896, 17 pp.

9. X. J. Zhang, K. D. Harns, N. L. Y. Wu, J. N. Murphy, J. M. Buriak, ACS Nano 4 (2010) 7021-7029.

10. S. S. Dinachali, W. Bai, K. H. Tu, H. K. Choi, J. Zhang, M. E. Kreider, L. C. Cheng, C. A. Ross, ACS Macro Letters 4 (2015) 500-504.

11. S. Rasappa, L. Schulte, D. Borah, M. A. Morris, S. Ndoni, Colliods and Interface Science Communications 2 (2014) 1-5.

12. S. B. Darling, Prog. Polym. Sci. 32 (2007) 1152-1204.

13. K. W. Gotrik, C. A. Ross, Nano Letters 13 (2013) 117-5122.

14. E. Kim, W. Kim, K. H. Lee, C. A. Ross, Adv. Funct. Mater. 24 (2014) 6981-6988.

15. J. Jeong. J. S. Ha, S. S. Lee, J. G. Son, Macromol Rapid Commun. 36 (2015) 1261-1266.

16. H. D. Koh, S. Park, T. P. Russell, ACS Nano 4 (2010) 1124-1130.

17. J. Chai, J. M. Buriak, ACS Nano 2 (2008) 489-501.

18. S. Rasappa, D. Borah, R. Senthamaraikannan, C. C. Faulkner, J. D. Holmes, M. A. Morris, J Nanosci Nanotechnol. 14 (2014) 5221-5228.

19. S. G. Jang, A. Khan, C. J. Hawker, E. J. Kramer, Macromolecules 45 (2012) 1553-1561.

20. S. Rasappa, J. M. Caridad, L. Schulte, A. Cagliani, D. Borah, M. A. Morris, P. Bøgglid, S. Ndoni, Rsc Adv. 5 (2015) 66711-66717. 
21. D. Borah, R. Senthamariakannan, S. Rasappa, B. Kosmala, J. D. Holmes, M. A. Morris, ACS Nano 7 (2013) 6583-6596.

22. W. Bai, A. F. Hannon, K. W. Gotrik, H. K. Choi, K. Aissou, G. Liontos, K. Ntetsikas, A. Alexander-Katz, A. Avgeropoulos, C. A. Ross, Macromolecules 47 (2014) 6000-6008.

23. W. Bai, K. G. Yager, C. A. Ross, Polymer 101 (2016) 176-183.

24. W. I. Park, K. Kim, H. I. Jang, J. W. Jeong, J. M. Kim, J. Choi, J. H. Park, Y. S. Jung, Small 8 (2012) 3762-3768.

25. J. H. Lee, Y. Kim, J. Y. Cho, S. R. Yang, J. M. Kim, S. Yim, H. Lee, Y. S. Jung, Adv. Mater. 27 (2015) 4814-4822.

26. S. Ndoni, P. Jannasch, N. B. Larsen, K. Almdal, Langmuir 15 (1999) 3859-3865.

27. S. Ndoni, C. M. Papadakis, F. S. Bates, K. Almdal, Rev. Sci. Instrum. 66 (1995) 1090-1095.

28. T. Li, Z. Wang, L. Schulte, S. Ndoni, Nanoscale 8 (2016) 136-140.

29. S. D. Bergin, Z. Sun, D. Rickard, P. V. Streich, J. V. Hamilton, J. N. Coleman, ACS Nano 3 (2009) 2340-2350.

30. P. Choi, T. A. Kavassalis, A. Rudin, Industrial \& Engineering Chemistry Research 33 (1994) 3154-3159.

31. T. H. Andersen, S. Tougaard, N. B. Larsen, K. Almdal, I. Johannsen, Journal of electron spectroscopy and related phenomena 121 (2001) 93-110.

32. I. F. Hsieh, H. J. Sun, Q. Fu, B. Lotz, A. Kevin, K. A. Cavicchid, Z. D. Stephen, S. Z. Cheng, Soft Matter 8 (2012) 7937.

33. J. Bonnet, G. Suissa, M. Raynal, L. Bouteiller, Soft Matter 11 (2015) 2308-2312.

34. A. F. Hannon, W. Bai, A. A. Katz, C. A. Ross, Soft Matter 11 (2015) 3794-3805.

35. M. A. Morris, microelectronic engineering 132 (2015) 207-217.

36. D. O. Shin, J. H. Mun, G. T. Wang, J. M. Yoon, J. Y. Kim, J. M. Y, Y. B. Yang, Y. Oh, J. Y. Lee, J. Shin, K. J. Lee, S. Park, J. U. Kim, S. O. Kim, ACS Nano 7 (2013) 8899-8907. 


\section{Supporting Information:}

Table SI. HSP of solvents used in all of the annealing experiments and Hansen solubility distances (www.hansensolubility.com) for PS and PDMS relative to the used solvents.

\begin{tabular}{|c|c|c|c|c|c|c|}
\hline \multirow[t]{2}{*}{ Selectivity } & \multirow{2}{*}{$\begin{array}{c}\text { Solvent/Solvent } \\
\text { mixture }\end{array}$} & \multirow{2}{*}{$\begin{array}{c}\underline{\delta}_{\mathbf{D}} \\
{\left[\mathrm{MPa}^{1 / 2}\right]}\end{array}$} & \multirow{2}{*}{\multicolumn{2}{|c|}{\begin{tabular}{c|c}
$\underline{\delta} \underline{P}$ & $\underline{\delta}_{\underline{H}}$ \\
{$\left[\mathrm{MPa}^{1 / 2}\right]$} & {$\left[\mathrm{MPa}^{1 / 2}\right]$}
\end{tabular}}} & \multicolumn{2}{|c|}{$\mathbf{R a}$} \\
\hline & & & & & PS & PDMS \\
\hline Non-solvent & dimethylformamide & 17.4 & 13.7 & 11.3 & 10.5 & 15.8 \\
\hline Neutral & dioxane & 17.5 & 1.8 & 9.0 & 6.5 & 6.1 \\
\hline PS & dioxane $_{1}$ :toluene ${ }_{1}$ & 17.7 & 1.6 & 5.5 & 4.7 & 4.2 \\
\hline PDMS & hexane $_{1}$ :toluene 1 & 16.5 & 0.7 & 1.0 & 6.6 & 3.3 \\
\hline
\end{tabular}

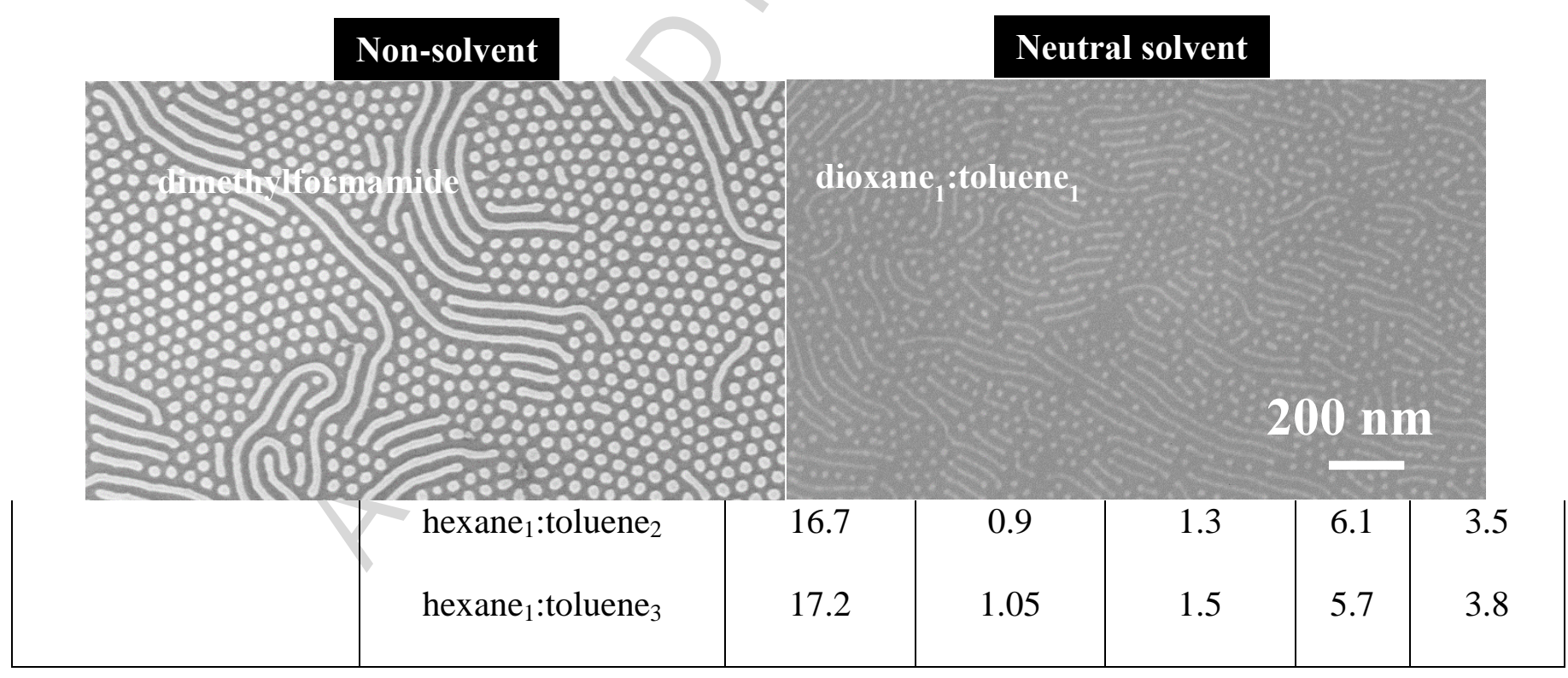

Figure S1. Top-down SEM images of the oxidized PDMS mask template on the Si substrate annealed under non-solvent and neutral solvent mixture. 


\section{PDMS selective}

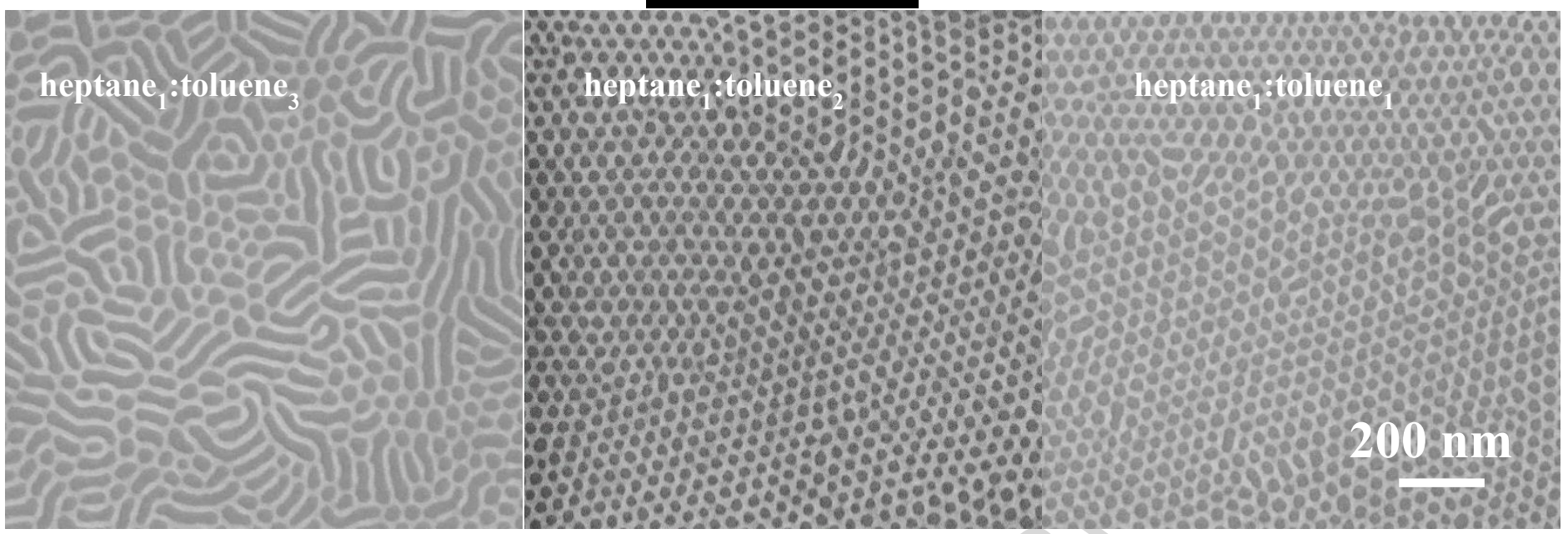

Figure S2: Top down SEM images of the oxidized PDMS mask template on the Si substrate under various annealing solvent mixtures of heptane:toluene. 


\section{Graphical abstract}

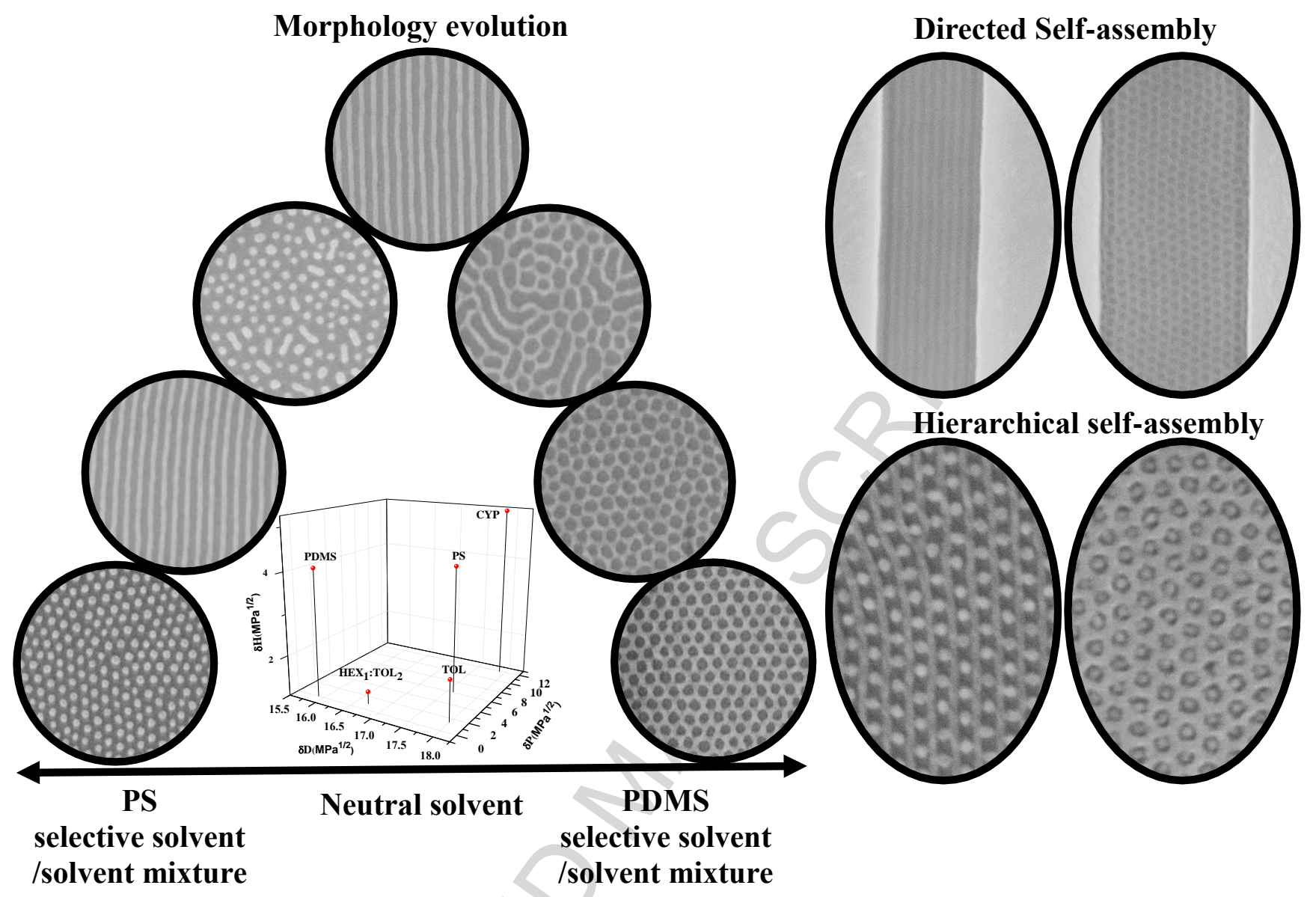




\section{Highlights:}

1. Morphology evolution was achieved by mere choice of annealing solvent.

2. One BCP can produce different templates by choosing right solvent based on HSP

3. A high etch contrast to substrate produces different nanostructures.

4. Directed and hierarchical directed self-assembly was demonstrated. 